\title{
Processo de Ensino da Língua Portuguesa para Imigrantes Haitianos
}

\author{
Proceso de Enseñanza del Idioma Portugués para los Haitianos \\ Imigrantes
}

Processo de Ensino da Língua Portuguesa para Imigrantes Haitianos

\author{
Maria Lourdes de Moura ${ }^{1}$ \\ Terezinha da Conceição Costa-Hübes ${ }^{2}$
}

\begin{abstract}
Resumo
Nos últimos tempos, mudanças significativas vêm ocorrendo no ensino de português como língua estrangeira (PLE), em decorrência da nova demanda de imigrantes que entra no Brasil. Estas pessoas chegam, muitas vezes, em situações de vulnerabilidade e precisam aprender a língua em caráter de urgência para a integração coletiva como convivência no trabalho e na comunidade. Neste cenário, dá-se conta de que o país não está preparado para acolher esta população e possibilitar o aprendizado da língua portuguesa, que seria a primeira ação de acolhimento. Conscientes dessa realidade, nosso objetivo, neste artigo, é apresentar nossa proposta de pesquisa que visa analisar como acontece o processo de ensino de língua portuguesa para um grupo de imigrantes haitianos, adultos, trabalhadores da linha de produção em fabrica de fios da cidade de Toledo, região oeste do Paraná. Nossa proposta é promover formas de ensino que contemplem a necessidade deste grupo, proporcionando práticas pedagógicas dentro de metodologias que permitam utilizar recortes da comunicação das práticas cotidianas destes sujeitos, apresentando-lhes um aprendizado da língua-alvo de forma significativa, a partir da perspectiva do multiletramento. Metodologicamente, trata-se de uma pesquisa qualitativa interpretativista, de cunho etnográfico, ancorada pela pesquisa-ação. Como base teórica, sustentamos a pesquisa na Linguística Aplicada (PENNYCOOK, 2006; MOITA LOPES 2006; dentre outros); em reflexões que alicerçam o letramento (FREIRE, 1987); nos Novos Estudos do Letramento (STREET 2003; BARTON 1994; BARTÃO e HAMILTON 1998; GEE 2004, 2005; DIONÍSIO 2007a, 2007b) e nas abordagens de Ensino da Língua Portuguesa como L2/LE (ALMEIDA FILHO, 2001, 2002).
\end{abstract}

Palavras-Chave: Ensino de Língua Portuguesa a Imigrantes; Língua de Acolhimento; Práticas de Multiletramento; Adultos Haitianos; Etnografia e Pesquisa-ação.

\section{Resumen}

En los últimos tiempos, cambios significativos vienen ocurriendo en la enseñanza de portugués como lengua extranjera (PLE), como consecuencia de la nueva demanda de inmigrantes que entra en Brasil. Estas personas llegan a menudo en situaciones de vulnerabilidad y necesitan aprender la lengua en carácter de urgencia para la integración colectiva como convivencia en el trabajo y en la comunidad. En este escenario, se da cuenta de que el país no está preparado para acoger a esta población y posibilitar el aprendizaje de la lengua portuguesa, que sería la primera acción de acogida. Conscientes de esta realidad, nuestro objetivo, en este artículo, es presentar nuestra propuesta de investigación que busca analizar como sucede el proceso de enseñanza de

\footnotetext{
${ }^{1}$ Doutoranda do Programa de Pós-Graduação Stricto Sensu em Letras - Nível de Mestrado e Doutorado, área de concentração em Linguagem e Sociedade, da Universidade Estadual do Oeste do Paraná - UNIOESTE Campus de Cascavel, Paraná, Brasil; malumoura891@ @otmail.com.

${ }^{2}$ Professora Doutora do Programa de Pós-Graduação Stricto Sensu em Letras - Nível de Mestrado e Doutorado, área de concentração em Linguagem e Sociedade, da Universidade Estadual do Oeste do Paraná - UNIOESTE Campus de Cascavel, Paraná, Brasil; tehubes@gmail.com.
} 
lengua portuguesa para un grupo de inmigrantes haitianos, adultos, trabajadores de la línea de producción en fabricación de hilos de la ciudad de Toledo, Región oeste de Paraná. Nuestra propuesta es promover formas de enseñanza que contemplen la necesidad de este grupo, proporcionando prácticas pedagógicas dentro de metodologías que permitan utilizar recortes de la comunicación de las prácticas cotidianas de estos sujetos, presentándoles un aprendizaje de la lengua objetivo de forma significativa, Multiletramento. Metodológicamente, se trata de una investigación cualitativa interpretativa, de cuño etnográfico, anclada por la investigación-acción. Como base teórica, sostenemos la investigación en la Lingüística Aplicada (PENNYCOOK, 2006, MOITA LOPES 2006, entre otros); En reflexiones que fundamentan el letramento (FREIRE, 1987); En los nuevos estudios de la lectura (STREET 2003, BARTON 1994, BARTÃO y HAMILTON 1998; GEE 2004, 2005; DIONISIO 2007a, 2007b) y en los enfoques de enseñanza de la lengua portuguesa como L2 / LE (ALMEIDA FILHO, 2001, 2002).

Palabras claves: Enseñanza de Lengua Portuguesa a Inmigrantes; Lengua de Acogida; Prácticas de Multiletramento; Adultos Haitianos; Etnografía e Investigación-acción.

\begin{abstract}
In recent times, significant changes have been occurring in the teaching of Portuguese as a foreign language (PLE), due to the new demand of immigrants entering Brazil. These people often come in situations of vulnerability and need to learn the language as a matter of urgency for collective integration as coexistence in work and in the community. In this scenario, one realizes that the country is not prepared to welcome this population and to enable the learning of the Portuguese language, which would be the first reception action. Aware of this reality, our objective in this article is to present our research proposal that aims to analyze how the Portuguese language teaching process happens for a group of Haitian immigrants, adults, workers of the production line in the wire factory of the city of Toledo, Western region of Paraná. Our proposal is to promote teaching methods that take into account the need of this group, providing pedagogical practices within methodologies that allow us to use clippings of the communication of the daily practices of these subjects, presenting them a learning of the target language in a significant way, from the perspective of the Multiletramento. Methodologically, this is a qualitative interpretative, ethnographic research, anchored by action research. As a theoretical basis, we support research in Applied Linguistics (PENNYCOOK, 2006, MOITA LOPES 2006, among others); In reflections that support literacy (FREIRE, 1987); (1998), in the New Studies of Literature (STREET 2003, BARTON 1994, BARTÃO and HAMILTON 1998, GEE 2004, 2005, DIONÍSIO 2007a, 2007b) and in Portuguese Language Teaching approaches as L2 / LE (ALMEIDA FILHO, 2001, 2002).
\end{abstract}

Keywords: Teaching Portuguese Language to Immigrants; Language of Reception; Multiletramento Practices; Haitian Adults; Ethnography and Action-research.

\title{
Introdução
}

Vivemos hoje a Era dos Direito e da Declaração Universal dos Direitos Linguísticos $(\text { DUDL })^{3}$. Esta representa, em relação à realidade brasileira, uma conquista de quase cinco séculos de trajetória histórica, que chegou a ser classificada, segundo Luna (2000), como linguicídio, ao descrever os conflitos que foram enfrentados para se conseguir conquistar uma política linguística no país. Porém, esta política ainda não consegue amparar muitas situações

\footnotetext{
${ }^{3}$ Foi Elaborada em junho de 1996, em Barcelona, tendo como pressupostos, a Declaração Universal dos Direitos do Homem (1948), o Pacto Internacional dos Direitos Civis e Políticos (1966), a Declaração sobre os Direitos de Pessoas Pertencentes a Minorias Nacionais ou Étnicas, Religiosas e Linguísticas (1992), a Carta Europeias sobre as Línguas Regionais ou Minoritárias (1992), a Declaração de Santiago de Compostela (1995), a Declaração do Recife de 09/10/1987, a Declaração Universal dos Direitos Coletivos dos Povos, Barcelona (1990), a Declaração Final da Assembleia Geral da Federação Internacional dos Professores de Línguas Vivas , Hungria (1991), entre outros documentos.
} 
emergentes que vêm ocorrendo nos últimos anos.

Enquanto se busca tais conquistas, o Brasil tem vivenciado, nos últimos tempos, uma realidade de multilingualísmo e, por esta razão, os estudos da linguagem, mais especificamente na área da Linguística Aplicada (LA), vêm desenvolvendo pesquisas no sentido de entender e abrir caminhos para facilitar estas interações. A partir dos últimos anos da década de 1990, pôde-se ver, segundo Grabe (2002), que as pesquisas da LA sobre ensino e aprendizagem de línguas e formação de professores que trabalham em contextos de multilinguismo começaram a enfatizar, dentre outras: as noções de conscientização linguística; a forma da aprendizagem de línguas; a aprendizagem a partir de interações dialógicas; os padrões para a interação professor-aluno; a aprendizagem baseada no contexto e o professor como pesquisador através da pesquisa-ação. A LA passou a englobar pesquisas que se centram primordialmente na resolução de problemas de uso da linguagem pelos participantes do discurso no contexto social. Além disso, buscou focalizar a linguagem do ponto de vista dos procedimentos de interpretação e produção linguística que definem o ato da interação linguística escrita e oral.

Por estarem diretamente empenhados na solução de problemas humanos que derivam dos vários usos da linguagem, os linguistas aplicados veem-se envolvidos em trabalhos com uma dimensão essencialmente dinâmica que busca a transformação do contexto de estudo. Nessa tentativa de propiciar mudanças, Rojo (2009) ressalta que o linguista aplicado passa a enfocar problemas concretos de conflito comunicativo e interpretá-los de maneira a contribuir para uma reflexão sobre as novas possibilidades de melhoria da qualidade de vida das pessoas.

Nessa perspectiva, Grabe (2002) descreve a expansão do campo do linguista aplicado e a maior especificação de seu papel como um agente que passa a se preocupar com problemas que trouxeram para seu domínio questões sobre aquisição de segunda língua, alfabetização, direitos de minoria em relação ao uso da língua materna e segunda língua, e formação de professores para trabalhar com estas classes heterogêneas.

Nesse sentido, os estudos da LA têm trazido grandes contribuições ao ensino e aprendizado de língua portuguesa para grupos de estudantes estrangeiros que chegam ao Brasil diariamente. Todavia, esse é um assunto que ainda carece de reforço no campo de estudos e pesquisas, na perspectiva de ampliar o cenário de formação acadêmico-profissional e de ensino do Português como Língua Estrangeira (doravante, PLE), no sentido de suprimir a carência de materiais, métodos e instrumentos de avaliação para melhor atendê-los. 
De acordo com Almeida Filho (1992), “O ensino de português como segunda língua, tem uma história de quase cinco séculos, no esforço de religiosos, no ensino de português a membros das nações indígenas" (ALMEIDA FILHO, 2002, p. 13). Mesmo tendo uma trajetória histórica, essa área está carente de materiais, métodos e formação de professores, principalmente diante da demanda de estrangeiros que vem crescendo diariamente no Brasil. São pessoas de outros países que chegam por conta das políticas de imigração e abertura para refugiados, motivados a conseguirem em nosso país uma condição de vida melhor, porém, em contraponto, se veem diante de uma realidade neoliberal excludente, na qual os direitos humanos muitas vezes são entendidos como direitos exclusivamente individuais e fundamentalmente civis e políticos, distantes dos direitos coletivos e culturais, conforme critica Candau (2008).

No entanto, percebe-se que o ensino do PLE no Brasil vem crescendo em vários sentidos nos últimos tempos, embora ainda se concentre em uma demanda que não atinge a nova realidade de imigrantes trabalhadores que buscam o Brasil por questão de sobrevivência, na maioria dos casos. O que se mais observa nessa direção, são cursos em escolas de idiomas ou em forma de extensão, ofertados pela comunidade acadêmica. Os primeiros, contudo, voltam-se, majoritariamente, a um público de trabalhadores de grandes empresas e suas famílias; já os últimos, prestam um serviço para alunos intercambistas e professores visitantes que permanecem de um a dois anos no Brasil. Existem ainda os cursos voltados aos turistas que chegam para curta jornada de intercâmbio, para cursos específicos, eventos, e outros.

Em contra partida, há uma emergência no ensino da Língua Portuguesa para esta nova realidade presente no país, que é o ensino de Português como Língua de Acolhimento (PLA) para imigrantes adultos, trabalhadores, que chegam ao Brasil em situação de miséria moral e, na maioria dos casos, com pouquíssimos recursos financeiros. Para esta demanda, carecemos também de políticas linguísticas que auxiliem na formação de profissionais para o ensino dessa língua alvo.

Diante dessa realidade e por residir em uma cidade - Toledo/PR - que acolhe muitos imigrantes vindos principalmente de países como o Haiti, Senegal, Bangladesh, Círia e outros, foi que despertou-nos o interesse em desenvolver uma pesquisa ${ }^{4}$ voltada para o tema Ensino de Língua Portuguesa para Estrangeiros. Nosso objetivo, nesta pesquisa, é analisar como

\footnotetext{
${ }^{4}$ Trata-se de uma pesquisa de doutorado em andamento, desenvolvida no âmbito do Programa de Pós-Graduação em Letras - Doutorado, da Universidade Estadual do oeste do Paraná - UNIOESTE, com vigência entre os anos de 2016 a 2019, sob a orientação da Profa. Dra. Terezinha da Conceição Costa-Hübes.
} 
acontece o processo de ensino de língua portuguesa para imigrantes haitianos adultos, trabalhadores da linha de produção em fábrica de fios de Toledo, região oeste do Paraná.

Como base teórica, sustentamos a pesquisa na Linguística Aplicada (PENNYCOOK, 2006; MOITA LOPES 2006; dentre outros); em reflexões que alicerçam o letramento (FREIRE, 1987); nos Novos Estudos do Letramento (STREET 2003; BARTON 1994; BARTÃO e HAMILTON 1998; GEE 2004, 2005; DIONÍSIO 2007a, 2007b) e nas abordagens de Ensino da Língua Portuguesa como L2/LE (ALMEIDA FILHO, 1997a, 1998).

Metodologicamente, a pesquisa será qualitativa interpretativista, de cunho etnográfico, ancorada pela pesquisa-ação. Como pesquisadora, colocamo-nos, ao mesmo tempo, como sujeito da pesquisa, uma vez que nosso propósito, como professora no ensino de PLE para um grupo de haitianos, é promover formas de ensino que contemplem a necessidade deste grupo, proporcionando práticas pedagógicas aplicáveis a estes contextos dentro de metodologias como português instrumental e/ou multiletramento.

Ressaltamos que nossa proposta de trabalho e nossas discussões acerca da questão da imigração na região oeste do Paraná, bem como nossas observações sobre a problemática do ensino de PLE, não têm aqui, a pretensão de ser solução para todas estas situações apresentadas, porém, reiteramos a necessidade de planejamento para que as partes constituintes destas ações de ensino possam se estruturar de forma coerente, harmonizando-se com as práticas necessárias.

Neste artigo, em específico, nosso propósito é apresentar como acontece o processo de ensino de língua portuguesa para um grupo de imigrantes haitianos, adultos, trabalhadores da linha de produção em uma fábrica de fios da cidade de Toledo, região oeste do Paraná. Ao colocarmo-nos como docente desse grupo, ousamos socializar uma tentativa de buscar possíveis soluções para a realidade em que se encontram estes estrangeiros, que a cada dia chegam ao Brasil e precisam de subsídios para enfrentar, principalmente os obstáculos na comunicação, de maneira que se sintam fortalecidos para uma melhor interação social, garantindo a sua permanência e subsistência em nossa sociedade.

Para dar conta do proposto, organizamos este texto da seguinte forma: primeiramente discorremos sobre a chegada dos imigrantes ao Brasil e a busca pela permanência; em seguida, abordaremos os aspectos culturais do grupo pesquisado; na sequência, discutiremos a necessidade da aprendizagem da língua portuguesa por parte dos imigrantes que chegam ao Brasil; dando continuidade às reflexões, dissertaremos sobre o ensino de PLA; e finalizando a discussão, apresentaremos como estamos organizando as aulas, pautadas em práticas de letramento. 


\section{A chegada recente dos imigrantes ao Brasil e a busca pela permanência}

Os imigrantes que chegaram, e continuam chegando a nossa região são oriundos, a maioria deles, de países dos Continentes Africano e Asiático, e vindos também do Oriente Médio. Vieram ao Brasil, muitos em situação de refugiados, em busca de uma melhor condição de vida. Estas pessoas chegam, na maioria das vezes, pelo estado do Acre (cidade do Rio Branco - Brasiléia) que tem o aspecto de tríplice fronteira, pedindo refúgio ao Brasil. Depois de receberem uma legalização provisória, buscam cidades onde se concentram indústrias e frigoríficos que possam empregá-los.

Em relação à chegada destes estrangeiros, mais especificamente dos haitianos no Brasil, a demanda iniciou com a participação brasileira na Missão das Nações Unidas para a estabilização no Haiti. Porém, junto com os haitianos, chegam centenas de imigrantes de outras nacionalidades diariamente, tais como: República Dominicana, Senegal, Nigéria, Colômbia, Camarões, Gâmbia, Nicarágua, República da Mauritânia, Equador, Serra Leoa, Bahamas, Gana, geralmente por meio da rota terrestre Equador-Peru-Bolívia-Brasil ou HaitiRepública Dominicana-Panamá- Equador-Peru-Bolívia-Brasil ${ }^{5}$.

Muitos deles, ao chegar ao Brasil, permanecem um tempo em São Paulo a procura de trabalho, porém, pela dificuldade que encontram, saem em busca de melhores oportunidades nas cidades da região sul do país onde se concentram muitas indústrias e frigoríficos. Este é o histórico de chegada de muitos haitianos e outras nacionalidades residentes hoje na cidade de Toledo, região Oeste do Paraná.

Os primeiros a chegar a Toledo foram senegalese, que em abril de 2014 procuraram trabalho no Frigorífico Sadia (BRF Brasil foods Toledo/Pr) e, em fevereiro de 2015, chegaram os primeiro haitianos a procura de emprego neste mesmo estabelecimento. A exemplo da Indústria BRF, outras várias empresas de Toledo e região empregam imigrantes, porém, com o critério de se empenharem no aprendizado da língua portuguesa. Assim, eles fixam residências, alguns com esposas e filhos que são matriculadas nos CEMEIS municipais ou escolas de Ensino Fundamental destas cidades, outros se organizam em "repúblicas" com

${ }^{5}$ Conforme informações apresentada em: ACNUR - Agencia da ONU para refugiados. <http://www.acnur.org/portugues/informacao-geral/trabalhe-no-acnur/>. Acesso em: $12 / 08 / 2016$. 
amigos, em geral, da mesma nacionalidade, evitando desta forma, os choques culturais. Em conversas informais com o grupo atendido, todos justificam a vinda ao Brasil, para melhor suas condições de vida, uma vez que o país de origem enfrenta sérios problemas com a pobreza, e consequentemente, com os altos índices de desemprego.

\section{Aspectos culturais}

$\mathrm{O}$ aspecto cultural é um dos pontos que precisa ser levado em conta quando se pensa em acolher esses imigrantes no país, pois são grupos heterogêneos de costumes, crenças e atitudes diferenciadas, e que estão se inserindo em um contexto maior. Conforme Candau,

As relações culturais não são relações românticas; estão construídas na história e, portanto, estão atravessadas por questões de poder, por relações fortemente hierarquizadas, marcadas pelo preconceito e pela discriminação de determinados grupos (CANDAU, 2008, p.51).

E por serem assim, em nossa região também não é diferente. Percebemos que os conflitos estão presentes em grande parte das relações que envolvem imigrantes e brasileiros. São culturas diferentes que, de alguma forma, se atravessam e se chocam, desestabilizando tanto os imigrantes quanto pessoas de nossa região que, muitas vezes, sentem-se ameaçados em suas relações culturais. Por outro lado, destaca-se especialmente a discriminação étnicoracial, já que o preconceito ainda encontra fortes raízes em uma região colonizada, em sua maioria, por cidadãos de origem europeia. Tudo isso tem causado segregação e constrangimento, principalmente aos senegaleses, haitianos, bengaleses e de outras nacionalidades descendentes dos continentes africanos e asiáticos que aqui se encontram.

Para amenizar estas questões, portanto, há necessidade de uma tarefa social e política, com bastante urgência. Conforme esclarece Candau (2008), “[...] é preciso investir em operações que interpelem o conjunto da sociedade, que partam de práticas e ações sociais concretas e conscientes e que tentem criar modos de responsabilidade e solidariedade entre as pessoas" (CANDAU, 2008, p.51). Nas próprias aulas de português, é interessante ter abordagens que discutam as questões culturais capazes de integrar as raízes históricas e as novas configurações, evitando uma visão de culturas com universos fechados e em busca do puro.

Os choques culturais ocorrem nas interações do dia a dia, principalmente no ambiente de trabalho, e se dá tanto entre grupos de estrangeiros de culturas diferentes, como no caso das relações entre haitianos e senegaleses, que em diversas situações não se apresentam de 
forma harmoniosa, quanto também com os próprios brasileiros em relação aos estrangeiros. Como exemplo, podemos citar a situação de alguns imigrantes senegaleses, os quais precisaram ser dispensados da empresa, porque, por questões religiosas, não aceitam receber ordens de líderes femininas no setor de trabalho.

Neste aspecto, há que se fazer um amplo trabalho social, em conjunto com os setores educacionais, no sentido de conscientização para o respeito à cidadania para com esses estrangeiros que necessitam do acolhimento local, a fim de que haja harmonia nas relações interculturais que medeiam esse encontro de diferentes culturas. Assim como, contar também com o esforço dos imigrantes, em agir com uma proposta de boa vizinhança.

\section{Aprendizagem da língua portuguesa: uma necessidade}

Percebemos, ainda, que no contexto socioeconômico em que a sociedade brasileira se encontra atualmente, os desafios para estes imigrantes em busca de trabalho e de permanência não são pequenos. Inicialmente há o problema da legalização; depois, a preocupação com o trabalho e a estabilidade. A maioria deles ocupam vagas do setor de produção, as quais geralmente são de mão de obra barata. Por conseguinte, são operários que trabalham no pesado e, em geral, ganham salários baixos. Mesmo já empregados, as preocupações não se findam, pois vem a necessidade da comunicação clara em português, muitas vezes como garantia para se manter no emprego, para entender e desenvolver a contento o que a empresa solicita. Em decorrência, a necessidade do aprendizado da língua portuguesa se torna urgente para eles, mas, para nós que aqui residimos e que lidamos com a docência, essa necessidade se desponta como uma nova realidade, pois precisamos ofertar um ensino PLA. Em geral, são estudantes adultos, trabalhadores braçais, que estão, por algum tempo, fora dos bancos escolares, e que não dispõem de recursos financeiros para pagar aulas particulares para aprender o português.

De acordo com a situação apresentada, temos, neste contexto, uma realidade de educação para jovens e adultos que necessitam de metodologias de ensino diferenciadas, contemplando, primeiramente, sua necessidade de interação à qual está submetida (um novo país, um novo contexto de trabalho, uma nova comunidade etc.). É preciso, também, pensar em suas experiências, sua cultura, enfim, sua bagagem de mundo, sem desconsiderar sua identidade e formação cultural que é diferente de nossa.

Nesse sentido, observamos um novo desafio para o ensino de língua portuguesa, especialmente aqui no Brasil. Precisamos encontrar a melhor forma de acolher esses 
imigrantes em nosso país, de modo que se sintam parte dele e de sua cultura. Para isso, precisamos investir no ensino da nossa língua. Mesmo que estudos voltados para o ensino de PLA tenha sido, nos últimos anos, alvo de reflexão por parte de vários autores, ainda há muito que precisa ser feito. Oliveira (2010) defende que estes dois aspectos são indissociáveis ao referir que "[...] quanto mais os imigrantes sentirem fazer parte do país de acolhimento e da sua sociedade, mais depressa estarão prontos para adquirirem as necessárias competências linguísticas (e outras) para se tornarem membros de pleno sucesso" (OLIVEIRA, 2010, p. 11).

A produção científica na área do ensino de LPE tem se configurado, no Brasil, a partir de alguns enfoques teóricos heterogêneos e apresenta-se, também, com diversas abordagens. Dentre os pesquisadores que contribuem com pesquisas nesta área, podemos citar Almeida Filho $(2001,2002)$ que apresenta reflexões relevantes sobre o ensino da língua portuguesa como L2 para estudantes estrangeiros que se encontram no Brasil em imersão para o aprendizado do português, e outros contextos de aprendizagem desta língua alvo. Porém, para o ensino do português como segunda língua ou como língua de acolhimento para imigrantes que procuram o Brasil em busca de trabalho, muitos em situações de vulnerabilidade, são poucas as pesquisas realizadas até o presente momento. Há uma emergente necessidade de políticas linguísticas que orientem e promovam condições para o ensino da língua portuguesa ocorrer de forma satisfatória para esta população. Faltam metodologias adequadas, assim como professores com formação para atender esta nova demanda. A maioria das propostas metodológicas encontradas está voltada para outros contextos de ensino de português como língua estrangeira e não contempla a necessidade de aprendizado emergencial destes imigrantes trabalhadores que estão perdendo sua vaga de trabalho por não entender as orientações de seus superiores na empresa, por não saber como manejar de forma correta os equipamentos, por não compreender as informações que lhes são repassadas. Além disso, falta-lhes conhecimento da língua para entender a folha de pagamento, conversar com um médico no ato de uma consulta, fazer comprar no supermercado e no comércio em geral, dentre outras ações de interação.

Conforme aponta Oliveira (2010), para que comece a fazer parte do dia a dia do Brasil, se faz necessário um aprendizado essencial: a língua portuguesa. É por meio dela que as pessoas conseguem expor seus pensamentos, preocupações, anseios e sentimentos. A língua é elemento crucial para o desenvolvimento das relações e para as trocas culturais. Logo, precisamos desenvolver habilidades para trabalhar com a língua de acolhimento. 


\section{O Ensino de Língua Portuguesa como Língua de Acolhimento}

O processo de ensino e aprendizagem PLA no Brasil tem como público-alvo uma comunidade com características bastante singulares, inserida num contexto até pouco tempo desconhecido.

Ançã (2005) afirma que a sociedade, ao acolher o imigrante, tem para oferecer PLA, que deverá ser entendida no seu sentido literal: "acolhida, refúgio em casa, forte, cidade, praça" (ANÇÃ, 2005, p.1). Nesse sentido, a nação local oferece a condição de acolhimento, colocando à disposição o aprendizado da sua língua oficial, porém, isso precisa ser feito com condições de aprendizagem, com metodologias adequadas a esta realidade.

Aranda e El-Madkouri (2006) explicitam que este conceito de PLA se tornou usual para vários autores como Fonseca e Gorraci (2007); Vala (2005); Bayan(2009); Oliveira (2007) e Grosso (2007). De acordo com Bayan (2009), o interesse teórico pela aprendizagem de uma PLA vem desde a década de setenta, no caso da Europa, devido às alterações verificadas no campo da imigração. Esta preocupação, demonstrada por meio de estudos e pesquisas, volta-se para a sociedade que recebe o sujeito imigrante e também para a necessidade de aquisição de uma segunda língua (L2) adquirida num contexto de imigração, com a finalidade de integração com o grupo local.

Nesse sentido, Ançã (2008) afirma:

O problema da língua de acolhimento coloca-se com toda a premência, sendo o domínio da LP uma das vias mais poderosas para a integração dos estrangeiros, tanto a nível individual (garantia da autonomia) como colectivo (harmonia social) (ANÇ̃̃, 2008, p. 74).

Conforme ressalta a autora, o imigrante trabalhador que necessita compreender a língua do país onde está residindo (temporariamente ou não) para a interação diária tanto na sociedade quanto em seu ambiente de trabalho, precisa estreitar o contato com essa línguaalvo, não só nas interações diárias de imersão, mas também em ambientes formais de ensino e aprendizagem. Para Oliveira (2010), o ensino de uma segunda língua em contexto de migrantes difere profundamente de qualquer outro ensino tradicional de uma segunda língua. A autora apresenta três pontos que mostram as especificidades deste processo:

A aquisição da segunda língua do migrante tem lugar em contextos tão variados como a sala de aula ou o meio envolvente; A aprendizagem da segunda língua tem lugar num ambiente de maior pressão social, legal, económica e outros, do que num contexto normal de aprendizagem. Têm 
necessidades linguísticas precisas, dependendo das necessidades e exigências práticas da sociedade em que estão integrados. A natureza multilíngue em situação de sala de aula. [...] Com grupos de migrantes, a base linguística (uma ou mais línguas, nem sempre adquiridas correctamente, com eventual iliteracia), o contexto linguístico (o uso de diferentes línguas em casa e fora da sala de aula) e a motivação ou pressão para aprender uma língua difere do contexto de aprendizagem de uma língua estrangeira (OLIVEIRA, 2010, p. 36).

De acordo com a autora, o ambiente de ensino e aprendizagem para a língua de acolhimento a este público-alvo, necessita de um planejamento preciso dentro dos recursos linguísticos que dizem respeito às necessidades diárias de suas interações comunicacionais. Vasconcelos (2005) defende que, no momento de organizar um curso de língua, que tenha como público-alvo trabalhadores imigrantes, devemos considerar dois pontos cruciais, sendo:

Facultar-lhe os meios para a comunicação mais facilitada em situação laboral, a fim de lhes permitir uma melhor integração e adaptabilidade às tarefas que lhes são confiadas; Estabelecer contactos sociais em local de trabalho, visto que este representa o local privilegiado de adaptação à sociedade de acolhimento (VASCONCELOS, 2006, p. 101).

Considerando as palavras da autora, entendemos que, em uma situação de ensino de PLA, se utilizarmos de situações reais, significativas para suas interações diárias laborais, e outras referentes às interações sociais, estaremos contemplando, de fato, as necessidades de aprendizagem deste grupo. Sabemos que os imigrantes precisam entender a língua portuguesa até como meio de garantir a permanência no trabalho, sendo este o caso de alguns haitianos, juntamente com outras nacionalidades de trabalhadores de algumas empresas da cidade de Toledo e demais localidades na região Oeste do Paraná.

Todavia, devemos lembrar, assim como afirma Cabete (2010), que "O imigrante adulto que se apresenta como aprendente da língua do país que o acolheu não parte de um ponto zero na sua aprendizagem, ainda que não conheça mais do que uma palavra portuguesa" (CABETE, 2010, p. 80). Precisamos considerar que o aprendiz traz consigo o seu percurso vivencial, o conhecimento de sua língua materna e de outras, suas experiências, sua representação do mundo, a visão que construiu acerca da língua portuguesa, e diversos outros conhecimentos acumulados, o que o revestem das mais variadas competências e/ou dificuldades face à aprendizagem da língua.

No entender de Oliveira, Faneca e Ferreira (2007),

As características pessoais dos sujeitos, os seus repertórios linguísticos, as motivações inerentes à aprendizagem da língua-alvo e os constrangimentos 
socioprofissionais e económicos são alguns dos elementos que não devem ser dissociados das questões que envolvem o processo de ensinoaprendizagem (OLIVEIRA, FANECA e FERREIRA, 2007, p. 8).

Outro aspecto importante na aprendizagem deste público-alvo é a questão da idade que os torna necessitados de metodologias e expectativas distintas dos demais aprendizes que também tem o português como língua não materna. O adulto, diferente da criança ou do jovem em idade escolar, além de trazer consigo uma vasta bagagem de mundo, precisa ser tratado como alguém que procura aprender essa "nova" língua por necessidade. E que, junto com interesses e expectativas, com sonhos e decepções, com entusiasmos e cansaços, apresenta uma mistura de sentimentos e emoções que os acometem em seu dia a dia, distante, a maioria deles, de suas famílias, o que poderá afetar decisivamente na aprendizagem.

Esperança (2006) afirma que os adultos, ao procurarem a formação, têm uma visão pragmática do que pretendem com a sua aprendizagem, e no entender deles “[...] só interessa aprender se o saber resultante tiver uma aplicação ao real e permitir resolver situações" (ESPERANÇA, 2006, p.60). Ou seja, o aprendizado precisa ser significativo para estes adultos, precisa fazer a diferença às suas necessidades.

\section{Uma proposta de pesquisa pautada em práticas de letramento}

Diante desta nova realidade de ensino do português como segunda língua para estes estrangeiros imigrantes, damo-nos conta da falta de metodologias adequadas para atender esta demanda. Por conseguinte, defendemos uma proposta de letramento ou multiletramento, voltada às práticas sociais, que considere os eventos de comunicação presentes em suas necessidades diárias, para sistematizar o ensino do PLA.

Motivadas por esta proposta, nossa pesquisa tem como tema o ensino da língua portuguesa para estrangeiros, no intuito de poder contribuir com uma possível proposta de letramento ou multiletramento para o ensino da língua portuguesa como PLA Segundo Silva e Araujo (2012), há aproximadamente três décadas, pesquisadores vêm produzindo estudos acerca do(s) letramento(s), tentando compreender a natureza complexa e multifacetada constitutiva desse fenômeno.

Em termos gerais, o letramento, conforme explica Soares $(1998,2003)$ diz respeito às práticas discursivas que fazem uso da escrita como práticas sociais. Como base teórica desta discussão, apresentamos, portanto, a proposta metodológica de Paulo Freire (1987) que objetiva estimular a alfabetização dos adultos mediante a discussão de suas experiências de vida, 
através de palavras presentes na realidade dos alunos, denominadas de "palavras geradoras". Estas, depois de selecionadas e exploradas contextualmente, são decodificadas para a aquisição do código linguístico e para a compreensão do mundo. O que se pretende com esse método é trabalhar o ensino da língua portuguesa com eventos do cotidiano, utilizando informações do conhecimento que cada um dos imigrantes traz, é apresentar o ensino da língua de forma significativa, dando-lhe possibilidade de refletir o aprendizado no uso cotidiano desta.

O método proposto por Paulo Freire (1987) foi desenvolvido no início dos anos 1960, no nordeste, onde havia um grande número de trabalhadores rurais analfabetos e sem acesso à escola, formando um grande contingente de excluídos da participação social. Esta atividade metodológica com os trabalhadores foi baseada nas experiências de vida das pessoas. Em vez de buscar a alfabetização por meio de cartilhas, Freire propôs que se trabalhasse com as chamadas "palavras geradoras" a partir da realidade do cidadão. Um trabalhador de fábrica poderia se alfabetizado a partir de palavras como "tijolo", "cimento"; um agricultor, por sua vez, aprenderia a partir de palavras como "cana", "enxada", "terra", "colheita" e outras. A partir da decodificação fonética dessas palavras, ia se construindo novas palavras e ampliando o repertório.

Esse método é dividido em três etapas. Na primeira etapa, denominada de Investigação, aluno e professor buscam, no universo vocabular do aluno e da sociedade onde vive, as palavras e temas centrais de sua biografia. Na segunda etapa, nominalizada de Tematização, o professor propicia para que os alunos codifiquem e decodificam esses temas, buscando o seu significado social, tomando assim consciência do mundo vivido. E terceira etapa, chamada de Problematização, aluno e professor buscam superar uma primeira visão ingênua, por uma visão crítica do mundo, partindo para a transformação do contexto vivido.

Estas etapas estão organizadas em cinco fases de aplicação, sendo elas:

$1^{\text {a }}$ fase: Levantamento do universo vocabular do grupo;

$2^{\mathrm{a}}$ fase: Escolha das palavras selecionadas, seguindo os critérios de riqueza fonética, dificuldades fonéticas - numa sequência gradativa das mais simples para as mais complexas;

$3^{\mathrm{a}}$ fase: Criação de situações existenciais características do grupo. Trata-se de situações inseridas na realidade local;

$4^{\mathrm{a}}$ fase: Criação das fichas-roteiro que funcionam como roteiro para os debates;

$5^{\mathrm{a}}$ fase: Criação de fichas de palavras para a decomposição das famílias fonéticas correspondentes às palavras geradoras.

A concepção freiriana procura explicitar que não há conhecimento pronto e acabado. Ele está sempre em construção. De acordo com esta concepção, as pessoas aprendem ao longo da vida 
e a partir das experiências anteriores. Com isso, cai por terra a tese de que alguém está totalmente pronto para ensinar e alguém está totalmente pronto para receber esse conhecimento, como uma transferência bancária. De acordo com Freire,

Existir humanamente, é pronunciar o mundo, é modificá-lo. O mundo pronunciado, por sua vez, se volta problematizado aos sujeitos pronunciantes, a exigir deles novo pronunciar. Não é no silêncio que os homens se fazem, mas na palavra, no trabalho, na ação-reflexão (FREIRE, 1987, p. 50).

O educador defende que não basta o sujeito apenas saber ler e escrever, mas fazer uso social e político desse conhecimento na vida cotidiana. E o grupo de imigrantes, trabalhadores, que chegam em nosso país, muitas vezes em situações fragilizadas, como é o caso dos que saíram de suas pátrias como refugiados, precisam estar atentos aos seus direitos humanos, para não serem explorados, por vezes até como escravos. Precisam aprender a língua, se movimentar no sentido de melhorias, entender com clareza as informações que lhe dizem respeito, não aceitar tudo sem reagir, pois, como orienta Freire (1987), os homens precisam se fazer nas palavras, no trabalho e na ação-reflexão, e não no silêncio.

Aliada às ideias de Freire (1987), nos amparamos também ao papel dos Novos Estudos do Letramento desenvolvidos por Bartão (1994) e Street (2003, 2012), que fornecem a base para intervenção em debates sobre o letramento em diferentes campos, apresentando os desafios ou incertezas que se destacam atualmente na área do ensino e aprendizado de línguas.

Street (2003) aborda sobre os Novos Estudos do Letramento, no que concerne ao letramento de adultos e afirma que neste contexto, "O papel dos Novos Estudos do Letramento é ajudar a articular e legitimar um movimento já desenvolvido que era muitas vezes antiacadêmico, devido a um sentimento de marginalização" (apud HAMILTON et al, 1994, p. 84).

Scribner e Cole (1981), analisando os usos da escrita por um grupo da Ibéria, observaram sobre dois ambientes nos quais esse grupo adquiria a escrita com objetivos diferenciados. O primeiro objetivo referia-se ao ambiente informal, do dia a dia, em que usava a escrita para estabelecer/manter relações de natureza informal entre si, e o segundo referia-se aos ambientes formais, como a escola e a religião, em que usava a escrita para cumprir as atividades escolares e religiosas. Dessa forma, podemos perceber, que os Novos Estudos do Letramento têm também uma grande importância no contexto das práticas sociais de uso da língua para estrangeiros. 
Os Novos Estudos do Letramento, segundo Street (2003), utilizam a perspectiva etnográfica para observar o que as pessoas fazem com seus conhecimentos de leitura e escrita e quais textos têm relação com suas vidas. Essa perspectiva busca compreender as práticas de letramento de comunidades e grupos específicos situados em um contexto sócio-histórico determinado. Ninguém é totalmente letrado, mas letrado “[...] em diferentes e determinados contextos [...]" (FISCHER, 2007, p. 30). O importante é entender o que realmente acontece nas comunidades investigadas, com o objetivo de “[...] expandir práticas comunitárias na área do letramento [...]" (STREET, 2003, p. 2) e não apenas para melhorar índices em testes de alfabetização.

De acordo com as colocações de Santos (2000), a atualidade tem se revelado como um momento único, particular, “[...] uma nova fase da história humana” (SANTOS, 2000, p.38), diferente de todas as situações que a antecederam. A ideia de movimento e mudança é, nesse momento, condição necessária para que a humanidade se transforme em todos os sentidos. Neste aspecto, percebemos uma grande mobilidade social, de idas e vindas culturais, em que não há mais fronteiras estanques que impeçam as pessoas de procurarem seus objetivos em outras estâncias.

Dessa forma, numa sociedade moderna ou pós-moderna, como a nossa, percebemos as práticas do letramento em toda a comunicação que nos cerca. O uso da escrita e da leitura são atividades diárias que não temos como fugir delas, seja na manipulação do cartão bancário, seja na leitura das placas, das receitas, das mensagens de e-mails e celular, estamos imersos nas diferentes práticas sociais.

Nesses contextos plurilíngues, a diversidade de linguagens em nosso meio cresce a cada dia, exigindo para o ensino de línguas, uma abordagem metodológica que atenda a pluralidade de culturas que cerceia todas as pessoas. E uma das propostas amplamente discutida é a Pedagogia dos Multiletramentos que colabora, de forma bastante significativa, para o ensino de línguas nestes contextos de diversidade cultural.

Segundo Rojo e Almeida (2012), A necessidade de uma Pedagogia dos Multiletramentos se deu em 1996, afirmada pela primeira vez em um manifesto resultante de um colóquio do Grupo de Nova Londres (doravante, GNL), um grupo de pesquisadores dos letramentos que, reunidos na cidade de Nova Londres (daí o nome do grupo), em Connecticut (USA), após uma semana de discussões, publicou um manifesto em seu favor intitulado $A$ pedagogy of multiliteracies - Designing social futures. De acordo com a autora, neste manifesto o grupo afirmava a necessidade de que a escola tomasse a seu cargo os novos letramentos emergentes em sociedade contemporânea. 
Para Rojo e Almeida (2012),

Diferentemente do conceito de letramentos (múltiplos), que não faz senão apontar para a multiplicidade e variedade das práticas letradas, valorizadas ou não, nas sociedades em geral, o conceito de multiletramentos - é bom enfatizar - aponta para dois tipos específicos e importantes de multiplicidade presentes em nossas sociedades, principalmente urbanas, na contemporaneidade: a multiplicidade cultural das populações e a multiplicidade semiótica de constituição dos textos por meio dos quais ela se informa e se comunica. (ROJO e ALMEIDA, 2012 p. 2, grifos da autora).

De acordo com a autora, a proposta de multiletramento vem ancorar as atividades pedagógicas de ensino que desenvolvemos, na perspectiva de atender a multiplicidade cultural de estudantes com quem convivemos diariamente. Todavia, para se consolidar efetivamente, essa proposta requer o uso diversificado de materiais que contemplem a multiplicidade semiótica da constituição dos textos que trazem a comunicação cotidiana destes sujeitos, por meio dos quais será trabalhado o ensino da língua portuguesa.

Explanando sobre o uso dos textos para o ensino de línguas, Rojo e Almeida (2012) afirma que "[...] no que se refere à multiplicidade de linguagens, modos ou semioses nos textos em circulação, as imagens e o arranjo de diagramação impregnam e fazem significar os textos contemporâneos - quase tanto ou mais que os escritos ou a letra" (ROJO e ALMEIDA, 2012, p.19). Para essa modalidade, a autora chama de multimodalidade ou multissemiose dos textos contemporâneos, que exigem multiletramentos. Ou seja, são textos compostos de muitas linguagens (ou modos, ou semioses) e que exigem capacidades e práticas de compreensão e produção de cada uma delas (multiletramentos) para fazer significar.

Considerando esse pressuposto teórico e a partir das necessidades observadas no novo cenário da comunidade local, pensamos em desenvolver um trabalho de ensino de língua portuguesa para estrangeiros residentes na cidade de Toledo-PR. Inicialmente, nos disponibilizamos, voluntariamente, para ofertar aulas a um grupo de haitianos que trabalham em uma indústria de fios nesta cidade. Para esta tarefa, primeiramente, o contato veio da própria empresa, que solicitou-nos auxílio nesse sentido. A empresa disponibilizou o local, organizou o grupo de imigrantes, selecionando os que apresentavam maior dificuldade para a comunicação. Também forneceu um material básico para cada um, como caderno, lápis, borracha e caneta. Disponibilizou-nos uma sala com mesas, cadeiras, projetor multimídia e outros materiais didáticos. O grupo constitui-se, a princípio, com dez pessoas, sendo sete homens e três mulheres, todos adultos, com idade entre 22 a 45 anos. 
Para a preparação das aulas, recorremos ao método de Paulo Freire (1987) que, conforme descrito, consiste em estimular a alfabetização (o ensino de língua portuguesa) dos adultos mediante a discussão de suas experiências de vida entre si, através de "palavras geradoras", ou seja, palavras presentes na realidade dos alunos, que são decodificadas para a aquisição da palavra escrita e da compreensão do mundo e da língua-alvo.

A partir do momento em que o grupo foi organizado, nosso primeiro encontro aconteceu no dia 13/03/2017, quando desenvolvemos a primeira etapa do método, conforme Freire (1987), qual seja, conhecer o universo vocabular dos alunos. Após a apresentação e a explicação do objetivo das aulas, buscamos, em conjunto com o grupo de imigrantes, conversar sobre suas principais dificuldades no dia a dia de trabalho ou nas interações sociais, na perspectiva de conhecer a realidade deles, o universo vocabular mais presente no seu cotidiano. A partir desta conversa, fizemos uma seleção dos temas e palavras geradoras, que nos serviram como base para a organização de cada aula. Esses temas e palavras geradoras assim se definiram:

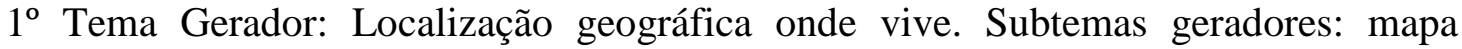
mundi, mapa do Brasil, mapa do Paraná, cidades pelas quais passou, mapa da cidade acolhedora, principais pontos de referência, principais avenidas e ruas, e outas. A partir das discussões desses temas e subtemas, trabalhamos com as seguintes palavras geradoras: Haiti, Brasil, São Paulo, Paraná, Curitiba, Cascavel, Toledo, Rodoviária, Prefeitura, Hospitais, Empresas, Indústrias, Comércio, Ruas, Avenidas, Lagos, e outras.

$2^{\circ}$ Tema Gerador: Costumes alimentares. Palavras geradoras: alimentos para o café da manha, almoço, janta, feijoada, macarronada, churrasco, carnes, e outras.

$3^{\text {o }}$ Tema Gerador: Partes do corpo. Palavras geradoras: cabeça, tronco, membros, estômago, rins, pulmão, coluna, coração, e outras.

$4^{\circ}$ Tema Gerador:- Área da saúde. Palavras geradoras: principais doenças, dengue, hospitais, postos de saúde, unidades de pronto atendimento (UPAS),medicamentos, especialidades na área médica, e outras.

$4^{\circ}$ Tema Gerador - EPIS na empresa. Palavras geradoras: uso dos equipamentos, quais são, para que servem, e outras.

$5^{\circ}$ Tema Gerador: Regras gerais da Empresa. Palavras geradoras: salário, atestados médicos, ficha-ponto, benefícios, descontos na folha de pagamento, atrasos, faltas, período de experiência, cumprimento de aviso prévio, adicional noturno, e outras. 
$6^{\circ}$ Tema Gerador: Musicas e festas brasileiras. Palavras geradoras: folclore brasileiro, festas tradicionais, porco no rolete, festa do costelão, café colonial, música popular brasileira, samba, forró, Centro de Tradições Gaúcha (CTGS), e outras.

$7^{\circ}$ Tema Gerador: Vestuários e cores. Palavras Geradoras: calça, camisa, camiseta, vestidos, shorts, blusas, saias, meias, bonés, tocas, casacos, jaquetas. Cores primárias, demais cores.

$8^{\text {o }}$ Tema Gerador:- Dinheiro. Palavras geradoras: valores em reais, cheques, cartão de credito, vale alimentação, e outras.

Para dar conta desses temas, a princípio, planejamos uma aula semanal, com carga horária de 2 horas, que acontece nas terças-feiras, no período da manhã, para facilitar a participação de todos os que trabalham nos demais período. As aulas encontram-se em andamento e estão sendo organizadas a partir dos temas e palavras geradoras e, até o momento, já trabalhamos com os seguintes temas: Localização geográfica, costumes alimentares, partes do corpo, área da saúde e EPIS na empresa. Todas as aulas estão sendo registradas com filmagens e servirão como dados que farão parte da nossa pesquisa em andamento. As aulas se estenderão até novembro de 2017.

A motivação para esta pesquisa partiu de dois questionamentos: a) Como ensinar língua portuguesa para estrangeiros adultos que falam em uma língua e escrevem em outra? b) Que método seria mais adequado para o ensino de língua portuguesa a estudantes estrangeiros, adultos, trabalhadores braçais, em situação de vulnerabilidade?

A partir dessas perguntas, procuramos elaborar um material didático para o ensino de português para estes estrangeiros, procurando trabalhar com temas relevantes que fizessem parte de seu universo e de sua realidade diária. A partir dos temas, procuramos apresentar conteúdos que possibilitassem a compreensão da língua-alvo e, consequentemente, interações significativas, de forma que pudessem se comunicar e desenvolver nas interações orais e escritas.

Para Almeida Filho (2001), uma das alterações que marcaram a afirmação do paradigma comunicativo foi a premissa de se considerar o próprio aluno como sujeito e agente no processo de formação através da nova língua, significando, assim, maior ênfase no que tem sentido para o aluno no seu aprendizado. $\mathrm{O}$ autor ainda acrescenta que,

A linguagem não pode ser tomada como objeto exterior ao aprendiz, mas sim como processo construtivo e emergente de significações e identidade. Aprender uma língua não é somente aprender outro sistema, nem passar informações a um interlocutor, mas construir no discurso (a partir de 
contextos sociais concretos e experiências previas) ações sociais e culturais apropriadas. (ALMEIDA FILHO, 2001, p. 28).

Ao considerar tais pressupostos, percebemos que um dos caminhos para o ensino da língua portuguesa para estes estudantes estrangeiros é a partir de uma metodologia de aprendizagem significativa, que lhes favoreça o uso cotidiano da língua portuguesa em suas necessidades comunicacionais. E, para isso, o aluno precisa ser alfabetizado nesta nova língua.

Paulo Freire (1991), abordando a alfabetização para estudantes adultos, esclarece que o conceito de alfabetização tem um significado abrangente, na medida em que vai além do domínio do código escrito, pois, como prática discursiva, “[...] possibilitar uma leitura crítica da realidade, constitui-se como um importante instrumento de resgate da cidadania e reforça o engajamento do cidadão nos movimentos sociais, que lutam pela melhoria da qualidade de vida e pela transformação social" (FREIRE, 1991, p. 68). No caso dos imigrantes haitianos, mesmo estando fora de sua pátria, de seu ambiente cultural, precisam se organizar, se comunicar, interagir na sociedade, ler e entender sobre seus direitos e deveres como cidadãos estrangeiro. Continua a necessidade de leitura do mundo, das coisas que o cercam.

Nesse sentido, a ação pedagógica precisa ser desenvolvida a partir da realidade do educando, identificando as situações significativas presentes no contexto em que ele está inserido. Para tanto, partir da realidade concreta significa reconhecer quais são as necessidades práticas que motivam estes estudantes estrangeiros à busca do conhecimento teórico. Para isso, a verificação, por meio da leitura de mundo do que os cercam, é a forma mais adequada para tentar apreender a realidade à nossa volta. Para Bachelard (1996):

A verificação é, em todos os níveis, o instante decisivo do conhecimento da realidade. Não é uma informação posterior, suplementar, que vem consagrar uma certeza; é um elemento da representação, é até seu elemento orgânico; ou seja, pela verificação é que a "apresentação" torna-se uma "representação". O mundo é "minha verificação", é feito de ideias verificadas, em oposição ao espírito, que é feito de ideias tentativas. Ou, em outras palavras, nossa única definição possível do real tem de ser feita na linguagem da Verificação. Sob essa forma a definição do Real nunca será perfeita, nunca estará concluída. Mas, será tanto melhor quanto mais diversas forem às verificações. (BACHELARD 1996, p. 273)

De acordo com o autor, a verificação do mundo, da realidade vivenciada pelos estrangeiros que estão inseridos nesse contexto é o que tem realmente significado para eles, desta forma, é o material mais propício para o trabalho com a língua. Relatos de história de 
vida, debates, temas que abordem o uso diário da língua-alvo, dentre outras, que possibilitam a identificação das situações experienciadas por eles, vão abrindo horizontes para os primeiros passos no processo de letramento e multiletramento.

Ao compreendermos que a inserção social desses sujeitos imigrantes vai ocorrer, mais facilmente, via aquisição da língua portuguesa, estamos investindo em uma ação de letramento, alicerçada nos pressupostos freirianos. Com tais ações, esperamos, em nossa pesquisa, comprovar que a aquisição dessa língua ocorre mais facilmente quando trabalhamos com temas que fazem parte de seu dia a dia e, consequentemente, de seus interesses mais emergentes.

\section{Considerações Finais}

O ensino de língua portuguesa para imigrantes adultos, trabalhadores, se encontra em uma fronteira porosa, em que os desafios vão se agigantando, na medida em que se começa o trabalho com estes sujeitos. Trata-se de investir em uma prática de ensino que se assenta em um terreno bastante árido ainda para fazer um trabalho a contento, pois os professores encontram-se, muitas vezes, sem os recursos necessários, tanto de material, quanto de conhecimento e métodos, e as urgências obrigam os profissionais ou leigos, que estejam abraçando esta causa, a encontrar uma saída.

Além destas dificuldades, precisamos também levar em conta a questão multicultural, pois os alunos que chegam até o ensino pertencem a grupos heterogêneos de costumes, crenças e atitudes que estão se inserindo em um contexto maior que, por vezes, a relação dos nativos estabelecidos nem sempre é harmoniosa com os que chegam de outras nacionalidades. Consequentemente, há a necessidade de uma tarefa social e política, conforme aponta Candau (2008), que envolva operações que interpelem o conjunto da sociedade, que partam de práticas e ações sociais concretas e conscientes e tentem criar modos de responsabilidade e solidariedade entre as pessoas.

Ressaltamos que nossa proposta de trabalho e nossas discussões acerca da questão da imigração recente na região oeste do Paraná, bem como nossas observações e preocupações acerca da problemática do ensino da língua portuguesa para esta demanda social não tem a pretensão de apresentar uma solução para todas as situações apresentadas. Todavia, reiteramos a necessidade de se investir em estudos e pesquisas que ousem apresentar novas propostas de planejamento para que as partes constituintes destas ações de ensino possam se 
estruturar de forma coerente, harmonizando-se com práticas que venham a suprir as necessidades emergentes.

Nossa colaboração, portanto, sustenta-se em uma proposta pautada em uma metodologia de ensino de língua portuguesa como língua de acolhimento, seguindo o método freiriano que propõe práticas de letramento a partir de temas geradores que fazem parte do dia a dia destes imigrantes. Esses temas de desdobrarão em conteúdos que possibilitem que os alunos compreendam melhor a estrutura da língua portuguesa. Assim esperamos poder colaborar, mesmo de forma bastante tímida, para amenizar as dificuldades que muitos imigrantes encontram no aprendizado da nossa língua.

\section{REFERÊNCIAS}

ALMEIDA FILHO, José Carlos Paes (Org.). Identidade e caminhos de Português para estrangeiros. Campinas: SP: UNICAMP, 2002.

O ensino de línguas no Brasil de 1978. E agora? Revista Brasileira de Linguística Aplicada, v. 1, n. 1, p. 15-29, 2001.

ANÇÂ, Maria Helena. Língua portuguesa em novos públicos. In: Saber (e) Educar N. 13 p. 71-87, Porto, 2008.

ANÇÂ, Maria Helena. À volta da língua de acolhimento. In: Encontro Regional da Associação Portuguesa de Linguística. ESE/Instituto Politécnico de Setúbal (CD-ROM), Setúbal, 2005.

ARANDA SOTO, Beatriz; MADKOURI, Mohamed El-. La Adquisicion de una L2 como lengua de acogida: hacia un modelo descriptivo de corte paragmático. Educacion y Futuro, Madrid, n. 14, p. 55-95, 2006.

BACHELARD, Gaston. A formação do espírito científico: contribuição para uma psicanálise do conhecimento. Rio de Janeiro: Contraponto, 1996.

BAYAN, Helena. Língua de Acolhimento: dos Princípios às Prática. 2009. Dissertação (Mestrado em Relações Interculturais), Universidade Nova de Lisboa, Lisboa, 2009.

BARTON, David. Literacy - an introduction to the ecology of written language. Cambridge/USA: Brackwell, 1994.

BARTON, David e HAMILTON, Mary. Local literacies. London and NY: Routledge, 1998

CABETE, Marta Alexandra Calado Santos da Silva. O processo de ensino-aprendizagem do português enquanto língua de acolhimento. 2010. Dissertação (Mestrado em Língua e Cultura Portuguesa) - Universidade de Lisboa, Lisboa. 
CANDAU, Vera Maria. Direitos Humanos, educação e interculturalidade: as tensões entre igualdade e diferença. Revista Brasileira de Educação. Ed. Vozes, v. 13, n 37. Rio de Janeiro, 2008.

DIONÍSIO, M. L. Educação e os estudos atuais sobre o letramento. Revista Perspectiva, Florianópolis, v. 25, n. 1, p. 209-224, 2007a.

Literacias em contexto de intervenção pedagógica: um exemplo sustentado

nos Novos Estudos de Literacia. Educação (UFSM), América do Norte, v. 32 n. 1, 2007 b.

Disponível em: Acesso em: 30 julho 2017.

ESPERANÇA, Joaquim. Ensino do Português como L2: A Escrita no Processo de Ensino Aprendizagem de Adultos. 2006. Dissertação (Mestrado em Ciências da Linguagem), Universidade Nova de Lisboa.

FISCHER, A. A construção de letramentos na esfera acadêmica. Tese (Doutorado em Linguística). Universidade Federal de Santa Catarina, Florianópolis, 2007.

FONSECA, Maria Lucinda. e GORRACI, Monica. (Coord.) Mapa de Boas Práticas Acolhimento e Integração de Imigrantes em Portugal, OIM e ACIDI, Lisboa, 2007.

FREIRE, Paulo. Pedagogia do oprimido. Rio de Janeira: Paz e terra. 1987.

A Educação na cidade. São Paulo: Cortez, 1991.

GRABE, Willam. Applied Linguistics: An Emerging Discipline for the Twenty-First Century. In: KAPLAN, Robert B. (Org.). The Oxford Handbook of Applied Linguistics. Oxford: Oxford University Press, 2002.

GEE, James Paul. Situated language and learning: A critique of traditional schooling. London: Routledge, 2004.

Why Video Games Are Good For Your Soul: Pleasure and Learning.

Melbourne: Common Ground, 2005.

GROSSO, Maria José. A actividade comunicativa em português do falante de língua materna chinesa. In Maria Helena Ançã (org.) Aproximações à língua portuguesa. Aveiro: Centro de Investigação Didáctica e Tecnologia na Formação de Professores, pp. 81-88, 2007.

LUNA, José Marcelo Freitas de. A política governamental para o ensino de Português a imigrantes alemães no Brasil: Geradora e destruidora da experiência da escola teutobrasileira. Revista da ANPOLL, nº. 8, p. 59 a 86, 2000.

MOITA LOPES, Luiz Paulo da. A transdisciplinaridade é possível em linguística aplicada? In: SIGNORINI, Inês; CAVALCANTI, Maria C. (Orgs.). Linguística aplicada e transdisciplinaridade: questões e perspectivas. Campinas: Mercado de Letras, 1998. OLIVEIRA, Gilvan Muller de (Org). Declaração Universal dos Direitos Linguísticos: Novas perspectivas em política linguística. São Paulo: Mercado de Letras, p. 113-127, 2003.

OLIVEIRA, Ana Maria. Processamento da Informação num Contexto Migratório e de Integração. In: GROSSO, Maria José dos Reis. (dir.) Educação em Português e Migrações. Lisboa: Lidel, 2010. 
OLIVEIRA, Ana Luísa, FONSECA, Rosa Maria; FEREIRA, Teresa. Integrar em língua portuguesa: considerações finais do Projecto Aproximações. In Maria Helena Ançã e Teresa Ferreira (orgs.) Aproximações à língua portuguesa: atitudes e discursos de não nativos residentes em Portugal. Actas do Seminário "Língua Portuguesa e Integração", Universidade de Aveiro, 2007.

ROJO, Roxane. Pedagogia dos Multiletramentos: Diversidade cultural e de linguagens na escola. São Paulo: Parábola Editorial, 2009.

ROJO, Roxane; ALMEIDA, Eduardo de Moura. Multiletramentos na Escola. São Paulo: Parábola Editora, 2012.

SANTOS, Milton. Por uma outra globalização: do pensamento único à consciência universal. São Paulo: Record, 2000.

SCRIBNER, Sylvia; COLE, Michael. The psychology of literacy. Cambridge: Havard University Press, 1981.

SILVA, Elizabeth Maria da e ARAUJO, Denise Lino de. Letramento: um fenômeno no plural. Rev. bras. linguist. apl. 2012, vol.12.

SOARES, Magda. Letramento: um tema em três gêneros. 3. ed. Belo Horizonte: Autêntica, 2009.

STREET, Brian. Abordagens alternativas ao letramento e desenvolvimento. Teleconferência Brasil sobre o letramento, outubro de 2003.

VALA, Jorge. (2005) Etnização e estratégias de relação cultural entre os imigrantes e os países de acolhimento: reflexões a partir do caso português. In BARRETO, A. (org.) Globalizção e Migrações, ICS, Lisboa, p. 274 a 289, 2005.

VASCONCELOS, Maria Helena. Educação de Adultos e Mutações Sociais, uma ponte para a autonomia. 2005. Dissertação (Mestrado em Educação), Universidade Nova de Lisboa, Lisboa. 